\title{
A RECATEGORIZAÇÃO NA RETEXTUALIZAÇÃO DE TEXTOS-FONTE PARA A CONSTRUÇÃO DE NOTÍCIAS
}

Maria Lourdilene Vieira Barbosa é doutoranda em Estudos Linguísticos pelo Programa de Pós-Graduação em Estudos Linguísticos da Universidade Federal de Minas Gerais e Professora Assistente da Universidade Federal do Piauí.

E-mail: vieira.marialourdilene@gmail.com

\section{Resumo}

Analisamos a recategorização de objetos de discurso em notícias em que se observa o processo de retextualização. Nesse gênero, as informações são apresentadas como fatos, sendo que a construção dos referentes adquire um valor de verdade. Nas análises, vimos que o sentido atribuído a um referente é apresentado vinculado ao texto-fonte, isentando o jornalista da responsabilidade de uma valoração axiológica com construção avaliativa de um referente.

\begin{abstract}
We have analyzed the re-categorization of the objects of discourse in the news in that we observe the retextualization process. In this genre, the information is presented as fact, and the construction of objects of discourse acquires a truth value. In the analyzes, the meaning attributed to a referent may be linked to source texts, which exempts the journalist of responsibility about axiological valuation with evaluative construction of a referent.
\end{abstract}

\section{1) Introdução}

Tida como um dos gêneros mais comuns da sociedade, a notícia participa da categoria dos gêneros jornalísticos que visam informar. Logo, costuma ser definida como um gênero de cunho essencialmente informativo, diferente de outros gêneros jornalísticos, como o editorial, por exemplo, que defende explicitamente um ponto de vista por meio de argumentos.

A notícia informa algo aparentemente novo, mas essa informação pode estar baseada em informações veiculadas em outros textos, que, no geral, participam de outros gêneros. Nestes, mesmo que as informações figurem como novas, estas parecem não ser recepcionadas como novidade como quando divulgadas na notícia, algo que corroboraria com a existência e o funcionamento social do próprio gênero notícia.

Soma-se a isso o tratamento dado à informação nas notícias, que circulam na sociedade com um valor de verdade. As informações são apresentadas como fatos sociais, e a audiência recebe e trata como fatos sociais as informações veiculadas nas notícias. Dessa forma, a construção referencial, com a categorização/recategorização de objetos de discurso, também adquire um valor de verdade, já que a referenciação é construída tendo em vista o sentido de todo o texto.

A noção de recategorização é definida por Apothéloz \& Reichler-Beguélin (1995) como a reapresentação dos objetos de discurso na cadeia textual, por meio da retomada anafórica. Este artigo analisa a recategorização dos objetos de discurso em casos de notícias em que se observa o processo de retextualização, entendido por Marcuschi (2010 [2000]) como a transformação de um texto em outro, em que são realizadas as adaptações necessárias. Assim, comparamos a apresentação de referentes no texto-fonte e sua reapresentação na notícia. Em se tratando de uma notícia retextualizada, em que o texto noticioso está fundamentado basicamente em um texto- 
fonte principal, o sentido do de um objeto de discurso é apresentado como estando vinculado ao texto utilizado como fonte principal.

Neste trabalho, analisamos notícias publicadas por portais jornalísticos em que se observam o processo de retextualização, segundo Marcuschi (2010 [2000]). Investigamos a construção referencial, sobretudo, a recategorização dos objetos de discurso, segundo Apothéloz \& Reichler-Beguélin (1995) e Mondada e Dubois (2003 [1995]) e sua relação com a construção de sentidos do texto.

\section{2) A referência e a relação língua - sociedade}

Inserido num sistema social, o homem, ao longo de seu desenvolvimento, assimila, através de seu sistema perceptual, coerções sociais determinadas e fundamentais à existência da própria sociedade, que, dentre outros moldes, determinam sua maneira de perceber e de entender o mundo que o cerca.

Blikstein (1985) defende a ideia de que não temos acesso ao real "Real", mas a um real fabricado "por nossa experiência perceptiva" (p. 47), que é adquirida por meio de uma construção e de uma prática social. Segundo o autor, é na prática social (a "práxis" ou o "conjunto das atividades humanas que engendram não só as condições de produção, mas, de um modo geral, as condições de existência de uma sociedade" (p. 54)), que se encontra o mecanismo gerador do sistema perceptual que vai "fabricar" o referente.

O autor reconhece que é por meio da dimensão da "práxis" que o homem passa a desenvolver mecanismos de "diferenciação" e "identificação", entendidos como a capacidade de diferenciar os componentes do mundo, a partir de traços distintivos que os identificam. Esses traços, na "práxis", adquirem valores de caráter "positivo/meliorativo" e "negativo/pejorativo" e, consequentemente, transformam-se em "traços ideológicos” que "vão desencadear a configuração de 'formas' ou 'corredores' semânticos, por onde vão fluir as linhas básicas de significação, ou melhor, as isotopias da cultura de uma sociedade" (BLIKSTEIN, 1985, p. 61, grifos do autor).

Muitas pesquisas se propõem saber como a língua é capaz de organizar o mundo de modo a torná-lo comum aos indivíduos de uma sociedade. Comum não no sentido de que todos o vejam exatamente da mesma forma, mas no sentido de que, seja qual for a designação linguística relacionada a dado objeto do mundo, um indivíduo que faça parte de uma sociedade seja capaz de atribuir uma significação. Acerca disso, a noção de referência aparece como uma explicação possível da relação que o indivíduo mantém entre a língua e a sociedade da qual faz parte.

A noção de referência, conforme é entendida hoje, passou por várias concepções, tanto no âmbito da linguística, como da filosofia da linguagem (CARDOSO, 2003). Dessa forma, os estudos que se preocupam em saber como a língua refere o mundo, além de numerosos, são posicionados a partir de concepções diferenciadas. Frege (1978), em seu Sobre o Sentido e a Referência, concebe o termo igualdade como equivalente ao de identidade, o que significa uma relação biunívoca 
entre objetos ou entre nomes ou sinais de objetos. Essa ideia considera que nomes ou sinais mantêm relação na medida em que referem um mesmo objeto mundano, ou seja, na medida em que designam uma mesma referência ${ }^{1}$.

Sobre o que se entende por referência, de Frege (1978) aos dias atuais, há um espaço enorme ocupado por muitos estudos que poderiam ser dispostos num continuиm acerca do entendimento dessa questão ${ }^{2}$. De um lado, teríamos uma concepção de base formal e lógica que dá à língua o papel de nomear entidades do mundo, que seriam discretizadas a priori a atividade discursiva. De outro, a concepção de que as entidades são construídas durante a produção discursiva em satisfação de um propósito comunicativo estabelecido para a produção de um sentido particular. De um lado a referência é tida como representação: uma palavra (um signo) representa uma entidade do mundo de forma fixa e imutável. De outro, a referência é tida como processo: ao longo da produção discursiva as entidades são construídas (e reconstruídas) de forma instável, porém ancoradas em práticas sociocognitivas. Neste, a representação acontece de forma instável.

Mondada (2005, p. 12) defende que, de um modo geral, a referência, neste âmbito, não é mais "considerada um problema estritamente linguístico, mas um fenômeno que concerne simultaneamente à cognição e aos usos da linguagem em contexto e em sociedade". Daí a necessidade de um estudo que esteja voltado para essa perspectiva considerar outros fatores, que não somente aqueles de ordem estritamente linguística.

É em função do entendimento de que a referência é construída ao longo da produção discursiva que autores como Mondada \& Dubois (2003 [1995]), Koch (2006) e Koch \& Elias (2007) postulam que o uso do termo referenciação, ao invés de referência, é mais adequado para a designação do processo. Marcuschi (2000a, p. 5) destaca que a noção de referenciação é utilizada "precisamente pelo fato de [se] admitir que a atividade referencial não é pura e simplesmente o ato de designar linguisticamente objetos do mundo".

Em todo o caso, é preciso considerar que tanto a língua constrói a realidade como é alimentada pelo que esta lhe oferece, na medida em que a toma como suporte para a construção referencial. O discurso constrói a referência com base em elementos do mundo real, embora considerar isso não signifique dizer que as palavras da língua representam os objetos, muito menos que as características dos objetos sejam dadas $a$ priori à atividade linguística.

Mondada \& Dubois (2003), ao tratarem da instabilidade constitutiva dos discursos, se reportam à noção de objeto de discurso. Nessa perspectiva teórica, os referentes são tratados como objetos de discurso porque não correspondem diretamente

\footnotetext{
${ }^{1}$ Frege utiliza a denominação referência no sentido comumente vinculado a referente (no caso de Frege, mundano).

${ }^{2}$ Cardoso (2003), em A questão da referência: das teorias clássicas à dispersão dos discursos, recupera todo o percurso da literatura, no âmbito da linguística e da filosofia da linguagem, no entendimento da noção de referência.
} 
a objetos do mundo real e são construídos na instância de discurso, tendo em vista os diferentes contextos, por sua vez, específicos e particulares. Logo, as palavras não constituem etiquetas que nomeiam os objetos ou a realidade mundana.

Considerando que o sentido textual é construído no curso da atividade discursiva, os significados das palavras se tornam plásticos, maleáveis, e se adequam às diferentes situações de fala e/ou escrita. Sobre o que se entendeu desde cedo sobre a recategorização lexical dos objetos de discurso na cadeia textual, Apothéloz \& ReichlerBéguelin (1995) definem o processo basicamente como a reapresentação lexical dos objetos de discurso ao longo da cadeia textual.

A categorização pode ser definida como a classificação de entidades do mundo a partir de suas semelhanças. Segundo Lakoff (1987, p. 5), categorizamos sempre que vemos algo como um "tipo de coisa", e isso é básico na organização do nosso pensamento, haja vista que a maioria de nossas palavras e conceitos designam categorias. Os estudos cognitivos deram à categorização um entendimento cultural e social de construção da realidade, considerando que a informação perceptiva do mundo em que vivemos é fundamental na construção de extensões de uma categoria, que considera as informações do mundo e o modo como respondemos a elas.

Apothéloz \& Reichler-Béguelin (1995) defendem que é preciso entender o léxico de uma língua "menos como um dado restritor, cujo emprego está sujeito apenas ao princípio de adequação referencial, do que como um conjunto de dispositivos extremamente maleáveis, continuamente trabalhados dentro e pelo discurso" (APOTHÉLOZ \& REICHLER-BÉGUELIN, 1995, p. 241). Desse modo, o léxico é visto tanto como um conjunto de palavras de uma língua para os diferentes fins comunicativos dos sujeitos, como (e principalmente) um conjunto de palavras cuja significação é maleável ao ponto de ser trabalhada dentro do discurso e pelo discurso, adaptando-se ao sentido construído em atividades particulares e concretas de comunicação.

Assim, há o uso de diferentes estratégias de referenciação, como a utilização de grupos nominais para a organização do discurso, conhecida na literatura como "rotulação" (FRANCIS, 2003), em que uma expressão lexical rotula uma informação ou um bloco de informações que aparecem no texto, dando a essas informações uma identidade referencial, um rótulo. Segundo Francis (2003, p. 192), "a principal característica do que é chamado de rótulo é que ele exige realização lexical, ou lexicalização".

Apothéloz \& Reichler-Béguelin (1995) defendem que o uso de determinadas categorias mantém relação com o contexto da situação e, em vista disso, torna-se adequado e produz sentido. Até mesmo em discursos com objetivos científicos as designações não são adquiridas ou determinadas de uma vez por todas, já que, constantemente, são submetidas à discussão e à revisão. Logo, em contextos científicos, "cada mudança de perspectiva sobre os objetos acarreta uma reformulação das classificações, portanto, das etiquetagens lexicais" (APOTHÉLOZ \& REICHLERBÉGUELIN, 1995, p. 241). 
No âmbito dos discursos de caráter argumentativo, há uma instabilidade mais aberta, no sentido de que as designações são usadas prioritariamente em função da construção de um ponto de vista. Apothéloz \& Reichler-Béguelin (1995, p. 241) afirmam que nesse sentido "se experimenta, em larga medida, o livre arbítrio e as estratégias persuasivas dos sujeitos falantes". Isso ocorre porque o tex to é construído em função de um sentido que adquire forma ao longo da produção textual, algo que, segundo os autores, pode ser facilmente visualizado em casos de anáforas lexicais: "domínio onde a liberdade de escolha nos meios linguísticos utilizados é maior pelo fato mesmo de o objeto designado já ser identificado, e em geral denominado, no modelo de mundo construído pelo discurso" (APOTHÉLOZ \& REICHLER-BÉGUELIN, 1995, p. 241 e 242, grifos dos autores).

\section{2) A retextualização entre gêneros discursivos}

Marcuschi (2000b), em Da Fala para a Escrita: atividades de retextualização, trata do processo de retextualização, preocupando-se em abordar mais especificamente as relações e diferenças entre as modalidades falada e escrita da língua. Logo, são analisados casos de textos orais retextualizados, em situações concretas, para textos escritos. $\mathrm{O}$ autor argumenta a favor da desmistificação de uma suposta supremacia da modalidade escrita da língua sobre a falada, para tanto, considera que "a retextualização não é, no plano da cognição, uma atividade de transformar um suposto pensamento concreto em um suposto pensamento abstrato" (MARCUSCHI, 2000b, p. 47 e 48, grifos do autor).

Dessa forma, o autor considera que, entre fala e escrita, é possível que haja diferentes combinações para ocorrência do fenômeno da retextualização. Reproduzimos abaixo o quadro elaborado e discutido por Marcuschi (2000b, p. 48):

Quadro 1: Possibilidades de retextualização

\begin{tabular}{|llllll|}
\hline 1. Fala & - & Escrita & (entrevista oral & - & entrevista impressa) \\
2. Fala & - & Fala & (conferência & - & tradução simultânea) \\
3. Escrita & - & Fala & (texto escrito & - & exposição oral) \\
4. Escrita & - & Escrita & (texto escrito & - & resumo escrito) \\
\hline
\end{tabular}

Fonte: Adaptado de Marcuschi (2000b, p. 48).

Considerando as várias possibilidades de combinação entre as situações de fala e escrita, Marcuschi assegura que lidamos diariamente com situações altamente automatizadas de sucessivas reformulações de textos,

numa intricada variação de registros, gêneros textuais, níveis linguísticos e estilos. Toda vez que repetimos ou relatamos o que alguém disse, até mesmo quando produzimos as supostas citações ipsis verbis, estamos transformando, reformulando, recriando e modificando uma fala em outra (MARCUSCHI, 2000b, p. 48). 
Como Marcuschi, Dell'Isola (2007) defende que a retextualização não deve ser entendida como "tarefa artificial", pois ela acontece cotidianamente, é um fato comum da vida prática, podendo ocorrer de maneira bastante diversificada, em situações rotineiras. Dell'Isola considera que cada vez que o conteúdo de um texto é retextualizado na constituição de um novo texto, temos a 'mesma coisa' dita de uma forma diferente, na qual estabelecemos uma nova situação comunicativa e cumprimos diferentes propósitos comunicativos. Para a autora, o mesmo conteúdo está sendo (re)textualizado de maneira diferente, onde temos dois gêneros que se distinguem por possuírem características distintas e também por realizarem diferentes ações sociais.

Nesse sentido, retextualizar consiste, sobretudo, em textualizar novamente em um outro texto as informações de um primeiro. Temos aí, no plano textual, um processo que rearticula linguisticamente informações já veiculadas. Porém, se atentarmos para o funcionamento sócio-histórico dos gêneros, a "mesma" informação, sendo veiculada por gêneros diferentes, é tratada de forma particular, que é própria do gênero.

Neste trabalho, entendemos gêneros a partir da ação social que eles realizam, na perspectiva da Sociorretórica. Miller (1984 [2009], p. 34), em seu "Gênero como ação social", inaugura uma definição importante para os estudos de gêneros nessa vertente, entendendo-os como "ações retóricas tipificadas fundadas em situações recorrentes". É claro, em Miller, que a noção de ação está intrinsecamente relacionada ao sujeito social, já que é este quem age numa determinada situação retórica, que lhe aparece como recorrente.

A recorrência, nesse caso, conforme nos assegura Miller, não pode ser entendida como material, mas "situações, como sendo, de alguma forma, 'comparáveis', 'similares', ou 'análogas' a outras situações” (MILLER, 1984 [2009], p. 30), que embora análogas, são únicas, porque cada situação é única. Dessa forma, a recorrência pode ser entendida como um fenômeno intersubjetivo e jamais ser confundida em termos materialistas.

Considerando que os gêneros realizam ações retóricas tipificadas em situações retóricas recorrentes, analisamos a recategorização no gênero notícia. Os exemplares de notícias serão analisados comparativamente aos seus textos-fonte principais, que participam, por sua vez, de outros gêneros, em casos que caracterizam o processo de retextualização.

\section{3) A recategorização na retextualização do texto-fonte para a construção da notícia}

\section{1) Aspectos Metodológicos}

Em um único texto, é possível encontrarmos diferentes estratégias utilizadas para a construção dos referentes, de modo que essas estratégias normalmente estão vinculadas ao sentido pretendido pelo locutor com o seu texto. Sabemos que a notícia é caracterizada como um gênero textual mais próximo da objetividade, sobretudo, por se 
constituir precipuamente de informações caracterizadas como atuais e de interesse para determinado(s) grupo(s) social(is).

Neste artigo, analisamos qualitativamente notícias oriundas de portais jornalísticos. Temos em vista apenas textos em que se observa o fenômeno da retextualização, entendido aqui como um texto que se constitui tendo em vista informações de outro. Logo, a análise examina tanto a notícia como o texto que serviu de base para a construção da notícia, considerando a apresentação das informações em ambos.

Nosso objetivo principal é analisar a recategorização dos objetos de discurso realizada na construção da notícia, considerando, para isso, a construção dos objetos de discurso no texto que serviu de base para as informações veiculadas na notícia e a construção dos objetos de discurso na notícia. Assim, analisamos textos divulgados em três portais jornalísticos do estado do Piauí - cidadeverde.com; portaldaclube.com; portalodia.com - em outubro de 2012.

Através dos portais jornalísticos também foi possível o acesso aos textos que serviram de fonte para a construção das notícias analisadas. Para a análise desenvolvida neste artigo, utilizamos notícias que tratam de dois eventos sociais ocorridos no ano de 2012: o desligamento do fornecimento de energia por algumas horas em vários estados do norte-nordeste e a interceptação de uma carta por agentes penitenciários na Penitenciária Regional "Irmão Guido", localizada na cidade de Teresina.

\section{2) Análise dos dados}

A opção por uma forma textual em detrimento de outras, na (re)categorização de um objeto de discurso, está vinculada ao sentido pretendido de construção desse objeto de discurso, algo que é comum em textos que participam de diferentes gêneros. A notícia, por sua vez, é um gênero caracterizado pela veiculação de informações tidas como recentes e de interesse de um ou mais grupos sociais. Na notícia, essas informações são normalmente apresentadas como fatos.

Dessa forma, a construção referencial, com a categorização/recategorização dos objetos de discurso, também adquire valor de verdade, já que o sentido atribuído a determinado objeto de discurso é parte do todo textual. Vemos, na figura 1, o título (manchete) e subtítulo de uma notícia fundamentada em duas notas oficiais, uma da Chesf e outra do Operador Nacional do Sistema Elétrico (ONS), ambas esclarecendo as causas do desligamento de energia ocorrido repentinamente em vários estados das regiões norte e nordeste, em outubro de 2012: 
Figura 1: Manchete de notícia de Portal de notícias online sobre 'apagão' ocorrido em outubro de 2012

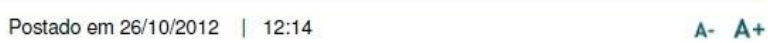

\section{Chesf e ONS divulgam notas sobre apagão que afetou $\mathrm{PI}$ e mais $\mathbf{1 1}$ estados}

De acordo com a ONS, o apagãofoi provocado por um curto-circuito na subestação Colinas-Imperatriz.

Fonte: http://portaldaclube.com/chesf-e-ons-divulgam-notas-sobre-apagao-qu... (Acesso: 27 out. 2012)

Na manchete (título) "Chesf e ONS divulgam notas sobre apagão que afetou PI e mais 11 estados" e subtítulo "De acordo com a ONS, o apagão foi provocado por um curto-circuito na subestação Colinas-Imperatriz" é colocado em evidência um objeto de discurso principal, sobre o qual a notícia trata principalmente: "o apagão". Essa notícia é construída a partir da retextualização de duas notas oficiais divulgadas pelos órgãos diretamente responsabilizados pelo ocorrido. Dessa forma, a nota da Chesf, reproduzida na Figura 2, trata do mesmo evento apontado na notícia:

Figura 2: Nota da Chesf esclarecendo as razões do desligamento de energia em outubro de 2012

Nota Chesf

A Companhia Hidro Elétrica do São Francisco - Chesf informa que o desligamento ocorrido às 00:14 Hs de hoje (horário de Brasília), dia 26/10/2012, não teve origem nas instalações ou equipamentos desta Empresa. O problemalfoi identificado, preliminarmente, na Subestação Colinas, localizada no Estado de Tocantins.

No momento da ocorrência, a Região Nordeste estava importando cerca de 2.500 megawatts de energia. A interrupçẫo brusca provocou instabilidade, acionando automaticamente o Sistema de Proteção da Chesf, que operou corretamente, desligando os demais equipamentos associados. As cargas começaram a ser restabelecidas a partir de 02:29 Hs de hoje, (horário de Brasília), dia 26/10/2012.

Ademais, o Operador Nacional do Sistema Elétrico - ONS é o órgão responsável pela coordenação e controle da operação das instalações de geração e transmissão de energia elétrica no Sistema Interligado Nacional - SIN, sob a fiscalização e regulação da Agência Nacional de Energia Elétrica Aneel, e repassará oportunamente as informações sobre origem do desligamento em comento.

Portanto, todo o Sistema Elétrico Brasileiro está, no momento, reunido no esforço de compreender as causas deste evento. Estima-se para ainda hoje a divulgação oficial que deverá ser feita pelo ONS.

Cordiais saudações,

Fonte: http://portaldaclube.com/chesf-e-ons-divulgam-notas-sobre-apagao-qu... (Acesso em: 27 out. 2012). 
Do ponto de vista referencial, embora trate do mesmo evento, o texto da Figura 2 apresenta o objeto de discurso a partir de uma expressão referencial diferente daquela encontrada no título e no subtítulo da notícia (Figura 1). Na nota, o objeto de discurso recebe diferentes categorizações, como "o desligamento", "o problema", "a ocorrência", "a interrupção brusca", "o desligamento em comento", "este evento", que corroboram com a construção do sentido do todo textual: a nota em questão é um documento oficial e visa esclarecer o ocorrido do ponto de vista técnico. Logo, há a opção por expressões referenciais que revelam uma maior neutralidade em relação à situação referida, embora esta seja referida no texto a partir de diferentes expressões referenciais, que constroem referencialmente uma única situação ou o mesmo objeto de discurso.

Já no título e no subtítulo da notícia (apresentados na Figura 1), a ocorrência ou o desligamento do qual trata a nota (na Figura 2) é categorizada como "o apagão", numa recategorização referencial explícita do objeto de discurso em foco. Sabemos que embora a notícia seja um gênero que circula socialmente para divulgar informações de maneira objetiva e imparcial, é também um gênero de mídia que visa sobremaneira a um público numeroso e diversificado, o que faz com que a informação seja estrategicamente apresentada para atrair a atenção desse público.

Se o desligamento brusco e repentino do fornecimento de energia é popularmente e informalmente categorizado como "apagão", a notícia faz uso desse conhecimento partilhado com seus leitores e rotula de "apagão" o que na nota é inicialmente categorizado como "desligamento". Essa estratégia faz com que a manchete da notícia adquira mais visibilidade e, consequentemente, atraia mais a atenção pública.

Temos, na Figura 3, o corpo da notícia em questão. Neste, o rótulo “apagão" não mais aparece, e são utilizadas expressões referenciais mais semelhantes àquelas encontradas na nota da Chesf (apresentada na Figura 2): 
Figura 3: Notícia de portal jornalístico sobre o desligamento de energia ocorrido em outubro de 2012

\begin{abstract}
A Companhia Hidro Elétrica do São Francisco (Chesf), responsável pela produção de energia elétrica no Piauí, divulgou nota nesta sexta-feira (26), esclarecendo que o desligamento de energiajocorrido no final da noite dessa quinta-feira (25) e início da madrugada de hoje não teve origem nas instalações ou equipamentos da empresa.
\end{abstract}

Conforme informou em nota, o Operador Nacional do Sistema Elétrico (ONS), houve um curto-circuito no segundo circuito da linha de transmissão em 500 kV Colinas-Imperatriz, que faz parte da interligação entre os sistemas Sul/Sudeste/Centro-Oeste e Norte/Nordeste.

Ainda segundo a ONS, 0 defeito foi eliminado pela atuação das proteções de retaguarda da subestação Colinas, que resultounno desligamento de oito circuitos de $500 \mathrm{kV}$ ja ela conectados.

De acordo com a Chesf, no momento da ocorrência a região Nordeste estava importando cerca de 2.500 megawatts de energia. Com a instabilidade provocada pe defeito o Sistema de Proteção da Chesf foi automaticamente acionado, desligando os demais equipamentos associados. Por volta das 2h29 de hoje, (horário de Brasília), as cargas começaram a ser restabelecidas.

Devido ao curto-circuito o fornecimento de energia afetou os nove estados do Nordeste, além de parte do Pará, Tocantins e Distrito Federal.

A ONS informou ainda que haverá, às 11 horas de hoje, em Brasilia, uma reunião do Comitê de Monitoramento do Setor Elétrico para avaliação do evento e suas consequências. No Rio de Janeiro, às 14 horas, será realizada uma reunião entre o ONS e os agentes envolvidos para a análise técnica da ocorrência.

Fonte: http://portaldaclube.com/chesf-e-ons-divulgam-notas-sobre-apagao-qu... (Acesso em: 27 out. 2012)

Como o objeto mundano construído referencialmente no texto da Figura 3 não diz respeito a um objeto ou a um ser material, mas a um processo, é possível identificarmos na cadeia textual expressões referenciais que categorizam o objeto de discurso a partir de diferentes fases do processo. Em tese, houve um problema em um dos sistemas geradores de energia, causando um curto-circuito, o que acionou automaticamente o sistema de proteção, que desligou repentinamente o fornecimento, ocorrendo a falta de energia. Esse processo inteiro é categorizado por diferentes expressões referenciais, tanto na nota da Chesf e na nota do ONS, como na notícia. No entanto, na manchete da notícia, o rótulo "apagão", sintetiza ou rotula o evento, de modo que o sentido desse rótulo está diretamente relacionado ao conhecimento compartilhado de eventos dessa natureza.

$\mathrm{Na}$ Figura 4, vemos a nota do ONS, que refere o evento como "ocorrência", "o desligamento de oito circuitos de 500 kV" e "essa ação", expressões referenciais que abordam o problema do ponto de vista técnico: 
Figura 4: Trecho de nota da ONS esclarecendo sobre desligamento de energia em outubro de 2012

Nota à Imprensa (26/10/2012)

Ocorrêncialafeta regiões Nordeste e Norte

À zero hora e 14 minutos de 26/10/12 houve um curto-circuito no segundo circuito da linha de transmissão em 500 kV Colinas-Imperatriz, que faz parte da interligação entre os sistemas Sul/Sudeste/Centro-Oeste e Norte/Nordeste e que é de propriedade da empresa transmissora TAESA (uma Sociedade de Propósito Específico cujos acionistas majoritários são a CEMIG e um fundo de investimentos). Este evento ocorreu em uma chave seccionadora do capacitor série da linha de transmissão, que ficou danificada.

O defeito foi eliminado pela atuação das proteções de retaguarda da subestação Colinas, que resultou no desligamento de oito circuitos de $500 \mathrm{kV}$ a ela conectados.

Essa ação causou a separação do sistema Norte/Nordeste do restante do Sistema Interligado Nacional (SIN) e, em seguida, a separacão dos sistemas Norte e Nordeste.

Fonte: http://portaldaclube.com/chesf-e-ons-divulgam-notas-sobre-apagao-qu... (Acesso em: 27 out. 2012)

A rotulação "apagão" não aparece no corpo da notícia (Figura 3), mas é utilizada tanto na manchete/título quanto no subtítulo (apresentados na Figura 1). Acreditamos que a opção pela utilização da expressão já na manchete se justifica pelo fato de que esta é a parte da notícia que tem mais visibilidade, já que possui a função de despertar a atenção para a leitura do conteúdo, que se encontra no corpo do texto.

Na Figura 5, temos a manchete de uma segunda notícia que informa sobre uma carta encontrada em um presídio da cidade de Teresina/PI.

Figura 5: Manchete de notícia publicada em portal jornalístico sobre carta encontrada em presídio de Teresina

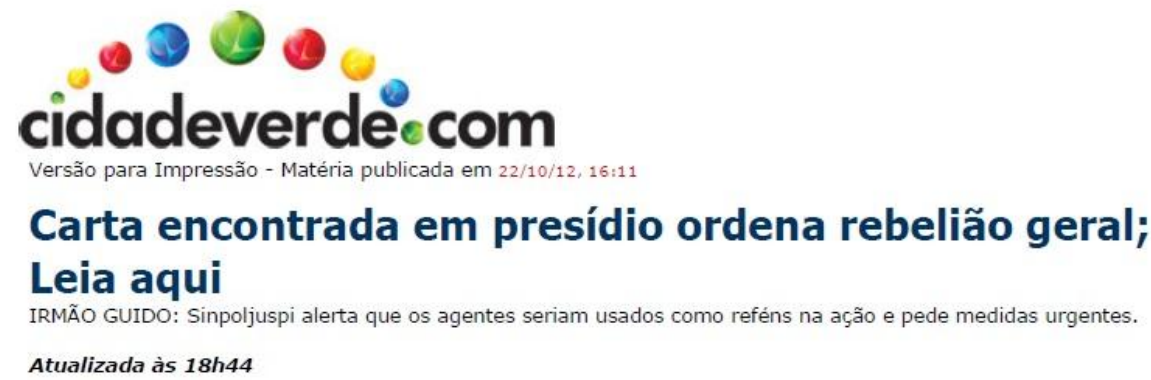

Fonte: http://www.cidadeverde.com/printpage.php?id=116092 (Acesso em: 22 out. 2012)

A manchete chama atenção tanto para o fato de ter sido encontrada uma "carta", como para o suposto propósito da carta de ordenar "rebelião geral" nos presídios de Teresina-PI. No subtítulo há ainda a informação de que agentes penitenciários seriam usados como reféns durante a ação dos presos. Na figura 6 , temos o conteúdo da carta

Revista Escrita

Rua Marquês de São Vicente, 225 Gávea-RJ CEP 22451-900 Brasil

Ano 2014. Número 19. ISSN 1679-6888.

escrita@puc-rio.br 
digitado, com algumas explicações entre parênteses feitas pelo portal jornalístico que deu acesso à carta:

Figura 6: Transcrição de carta encontrada em presídio de Teresina

\begin{abstract}
o Cidadeverde.com teve acesso a uma cópia da carta, reproduzida abaixo. As observações em parênteses são da redação do portal, para melhor compreensão do leitor.

"Salverapaziada do anex 2 (anexo 2 - triagem). Aqui eq rapazeada PVC (pavilhão C) e o seguinte nós já conversamo com a rapaziada do B e do PVD (Pavilhão D). Pois a rapaziada apoiou a gente vai começar aqui no PV.C então nos vamos quebrar o PVB (pavilhão B). E o nosso objetivo e pedir nossa regalia que nos tem direito e modar a direção do sistema pois a rapaziada la da custodia entrou em contato com nos e disse que eles conseguiram tirar o Wilsin (vice-diretor da Casa de Custódia e chefe do grupo de vistoria) e assim so nos se unir que nos vamos conseguir nosso objetivo e só nossa melhoria pois a maioria dos irmão aqui centenciados porque so nos não tem direito pois em Parnaíba os caras tem direito a $T V$ e ventiladores e som pois nos so vamos conseguir se nos quebrar esta porra não e para gerrar morte mas para nossa segurança nós vamos quebrar o PV.A (pavilhão A). Eo especial é aí vocês sabe que aí no anex 1 (triagem) também tem us caras que náo serve que trabalham para a polícia agora vocês ficam na ativa nos só vamos esperar resposta do SP (seria uma resposta de São Paulo). Dependendo do que os irmão decidirem, nós começamos o bagulho e vamos sustenta para chamar a atençao da emprensa e das autoridades nós vamos mandar as responsas para vocês e depois da visita tem tudo para dar certo. Virmezalladróes. Fiquem na paz de um alo no Júnior e no resto da rapaziada. Ass: a rapaziada do PV.C"
\end{abstract}

Fonte: http://www.cidadeverde.com/printpage.php?id=116092 (Acesso em: 22 out. 2012)

Na carta em questão, temos uma conclamação da população presidiária para uma revolta de objetivos claros: "pedir a nossa regalia que nos tem direito ['TV e ventiladores e som'] e modar a direção do sistema". O locutor é a "rapaziada do PVC" se dirigindo ao interlocutor, a "rapaziada do anex 2". A "rebelião" recategorizada na manchete da notícia apresentada na Figura 5 é construída referencialmente na carta, supostamente escrita por presidiários, a partir diferentes ações concomitantes: "quebrar o PVB", "pedir nossa regalia que nos tem direito e modar a direção do sistema", "quebrar esta porra", "quebrar o PV. A".

Não há, na carta, uma rotulação única para a ação dos detentos. Essa rotulação acontece posteriormente na manchete da notícia, que tem em vista a expressão referencial mais comumente utilizada para classificar eventos dessa natureza, uma "rebelião". Tal nomenclatura reflete, portanto, o conhecimento social de que as revoltas que acontecem em presídios ou casas de detenção são denominadas de rebelião. Tal palavra per si já carrega uma carga ideológica e cultural que, normalmente, amedronta a população, logo, aparecendo na manchete de uma notícia, certamente despertará a atenção do público leitor.

Na Figura 7, temos uma terceira notícia, reproduzida na íntegra, que também trata do evento que ora tratamos: 
Figura 7: Notícia de Portal jornalístico sobre carta encontrada em presídio de Teresina

\begin{tabular}{l|l} 
Postado em 22/10/2012 $21: 29$ &
\end{tabular}

A- $\mathrm{A}+$

\title{
Portal da Clube tem acesso à carta encontrada na Irmão Guido; Confira!
}

\author{
Para justificara açāo a "rapaziada do|PV. C" cita a Penitenciaria \\ Fontes Ibiapina, em Parnaíba, como "modelo" de unidade prisional]do \\ ponto de vista dos presidiários
}

\begin{abstract}
O Portal da Clube teve acesso à carta interceptada durante vistoria de rotina na Penitenciária Regional Irmão Guido, na zona rural de Teresina. Na carta assinada pela "Rapaziada do PV. C"- uma provável referência a Pavilhão C -, o remetente fala em "quebrar o Pavilhão B" para conseguir regalias como televisão, som e ventilador.

Para justificara ação a rapaziada do PV. C" cita a Penitenciaria Mista Juiz Fontes Ibiapina, localizada em Parnaíba, como "modelo" de unidade prisional do ponto de vista dos presidiários.

Ao contrário do divulgado mais cedo, a carta interceptada na Irmão Guido não determina o assassinato de agentes penitenciários. Em um determinado momento, o remetente diz que o objetivo não é matar, mas se proteger.

No fim da carta, o remetente faz a sua única referência a um preso específico. Trata-se de Júnior, mas a carta não permite identificar com certeza quem ele é.
\end{abstract}

Fonte: http://portaldaclube.com/portal-da-clube-tem-acesso-a-carta-encontrad... (Acesso em: 22 out. 2012)

Na notícia apresentada na Figura 7, a referência a "rebelião" fica apenas subentendida, tendo em vista que "a carta" já é apresentada ao interlocutor como um objeto de discurso conhecido, como informação dada. Nesse sentido, há a utilização da expressão referencial "a ação", na referência à situação tratada na carta. No subtítulo e corpo da notícia, há o cuidado de deixar claro que as informações apresentadas são oriundas da carta, ainda que o locutor se utilize de recategorizações referenciais nas informações que destaca.

Quanto a isso, temos, no subtítulo e corpo da notícia, a expressão referencial “"modelo' de unidade prisional", imediatamente seguida da informação "do ponto de vista dos presidiários", rotulando a informação encontrada na carta que "em Parnaiba os caras tem direito a TV e ventiladores e som". A informação trazida pela notícia na expressão referencial “"modelo' de unidade prisional” não significa exatamente o ponto de vista dos presidiários, mas a interpretação que o jornalista faz da informação da carta, que cita o presídio de Parnaíba como justificativa para o argumento de que presidiários têm direito a "regalias" como TV, ventilador e som.

Por duas vezes a notícia faz referência ao locutor da carta, utilizando a expressão referencial com a qual este se autodenomina em seu texto, "a rapaziada do PV. C". No entanto, a opção pela expressão referencial utilizada pelos próprios detentos é destacada por aspas, numa citação por meio do discurso indireto livre. Na referência ao locutor da 
carta, sem a utilização das aspas que destacam a expressão referencial utilizada pelos presidiários, a expressão referencial utilizada é "o remetente", que recategoriza a expressão referencial utilizada anteriormente "a rapaziada do PV. C".

Sabemos que a notícia opta por usos linguísticos que caracterizam uma linguagem formal. Isso pode explicar a escolha de uso de uma expressão referencial em detrimento de outra utilizada textualmente na própria fonte da notícia. Comparando os dois textos, o noticioso e a fonte, no qual o primeiro retextualiza informações contidas no segundo, é clara a mudança de construção e, mesmo de escolhas lexicais na construção dos objetos de discurso que fazem parte do 'mundo' construído discursivamente em ambos os textos.

Logo, vemos claramente uma mudança na apresentação das informações. Estas tratam do mesmo evento social, mas são categorizadas e recategorizadas a partir de expressões referenciais diferentes. Cada uma dessas expressões é escolhida em função da construção de sentido do texto em questão: no texto-fonte ela aparece para atender um objetivo em específico, na notícia, a "mesma" informação é recategorizada para atender ao objetivo específico da notícia.

No caso da notícia, embora seja utilizada uma expressão referencial diferente para re/categorização de um objeto de discurso, este é apresentado como vinculado a outro texto, que é apresentado para o leitor como sendo a fonte principal da notícia. Portanto, podemos afirmar que a opção do jornalista em separar sua voz da voz dos sujeitos envolvidos na notícia, destacando a informação oriunda de outros textos que lhe servem como fontes, pode funcionar como uma estratégia de isenção da responsabilidade de uma valoração axiológica, na construção de um referente de forma avaliativa. Por outro lado, essa opção pode dar respaldo à notícia, dada à repercussão que um texto-fonte possa ter para um determinado grupo social.

\section{4) Considerações finais}

Pelas análises dos dados, percebemos como diferentes textos se utilizam de diferentes estratégias para a construção de sentidos. $\mathrm{Na}$ análise da recategorização dos objetos de discurso na notícia, em comparação com a construção dos objetos de discurso do texto utilizado como fonte, vimos que a recategorização acontece seguindo uma tendência própria dos textos midiáticos, que visam sobremaneira atingir um grande número de leitores e, para tanto, utilizam-se de estratégias para chamar a atenção desse público leitor.

Dessa forma, o conhecimento comum de que a notícia é um gênero objetivo que visa, sobretudo, informar fatos para a sociedade é contraditório ao que vimos nas análises, tendo em vista que a notícia é um gênero, e todo gênero reproduz um ou mais discursos, que são ideológicos, como já nos disse Bakhtin (2003). Sabemos que um texto é construído com propósitos comunicativos determinados e, no caso da notícia, para chamar a atenção do leitor, são utilizadas estratégias linguísticas, como a recategorização referencial dos objetos de discurso. 
A opção por uma expressão referencial que despertaria a atenção de um grande público revela uma valoração axiológica, pois direciona a opinião pública para um sentido pré-determinado já na escolha de uma expressão referencial em detrimento de outras. No mesmo sentido, quando há a escolha por uma expressão referencial oriunda de uma interpretação da informação do texto-fonte pela instituição jornalística, há o direcionamento para a construção de um sentido que é construído especificamente na notícia.

\section{Referências}

APOTHÉLOZ, D.; REICHLER-BÉGUELIN, M. J. Construction de la référence et stratégies de désignation. In: BERRENDONNER \& REICHLER-BÉGUELIN, M-J. (eds.). Du sintagme nominal aux objects-de-discours: SN complexes, nominalizations, anaphores. Neuchâtel: Institute de linguistique de l'Université de Neuchâtel, 1995, p. 227-271.

BAKHTIN, M. Os gêneros do discurso In: Estética da criação verbal. São Paulo: Martins Fontes, 2003. pp. 261-306.

BLIKSTEIN, I. Kaspar Hauser ou A Fabricação da Realidade. São Paulo: Cultrix, 1985.

CARDOSO, S. H. B. A questão da referência: das teorias clássicas à dispersão de discursos. Campinas: Autores Associados, 2003.

DELL'ISOLA, R. L. P. Retextualização de gêneros escritos. Rio de Janeiro: Lucerna, 2007.

FRANCIS, G. Rotulação do discurso: um aspecto da coesão lexical de grupos nominais. In: CAVALCANTE, M. M.; RODRIGUES, B. B.; CIULLA, A. (Org.) Referenciação. São Paulo: Contexto, 2003.

KOCH, I. V. Desvendando os Segredos do Texto. São Paulo: Cortez, 2006.

\& ELIAS, V. M. Referenciação e progressão referencial. In: Ler e Compreender: os sentidos do texto. São Paulo: Contexto, 2007, p. 123-135.

LAKOFF, G. Women, fire, and dangerous things: what categories reveal about the mind. Chicago: The University of Chicago, 1987.

MARCUSCHI, L. A. Referenciação e Progressão Tópica: aspectos cognitivos e textuais. Revista do GELNE, vol. 2, $\mathrm{n}^{\mathrm{o}}$ 2, 2000a, p. 1-11. Disponível em: www.gelne.ufc.br/revista_ano2_n2_12 (Acesso em 02/04/09).

$2000 b$.

Da fala para a escrita: atividades de retextualização: São Paulo: Cortez, 
MILLER, C. R. Gênero como ação social In: Gênero textual, agência e tecnologia. Recife: Ed. Universitária da UFPE, 2009.

MONDADA \& DUBOIS, D. Construção dos objetos de discurso e categorização: uma abordagem dos processos de referenciação. In: CAVALCANTE, M. M.; RODRIGUES, B. B.; CIULLA, A. Referenciação. São Paulo: Contexto, 2003 [1995].

MONDADA, L. A referência como trabalho interativo: a construção da visibilidade do detalhe anatômico durante uma operação cirúrgica. (Trad. Ingedore V. Koch) In: KOCH, I. V. Referenciação e Discurso. São Paulo: Contexto, 2005, p. 11-32. 